\title{
EFEITO DO PRÉ-TRATAMENTO COM ÁGUA A 93ํㅡ NA TAXA DE DESIDRATAÇÃO OSMÓTICA DA ACEROLA
}

\author{
J. S. NASCIMENTO' ${ }^{1}$, V. A. SILVA ${ }^{1}$, R. F. DE OLIVEIRA ${ }^{1}$ e SILVA. A. A. R. ${ }^{1}$ \\ ${ }^{1}$ Universidade Federal da Paraíba, Departamento de Engenharia Química \\ E-mail para contato: verusckaaraujo@gmail.com
}

\begin{abstract}
RESUMO - O Brasil é o terceiro maior produtor mundial de frutas. Porém, durante o período de safra, parte da produção é perdida devido aos baixos preços, o transporte e armazenamento realizados de maneira inadequada. A acerola, cujo nome cientifico é Malpighia emarginata DC, têm sido uma fruta largamente cultivada nos últimos anos na região nordestina. As frutas in natura com o passar do tempo se decompõe naturalmente e a desidratação osmótica é uma alternativa rentável a esta decomposição. A desidratação osmótica permite uma redução parcial da água do fruto, por imersão em solução de sacarose. No presente trabalho foi estudado o efeito do pré-tratamento térmico com água a $93{ }^{\circ} \mathrm{C}$ durante 5 segundos, seguindo para a desidratação osmótica em soluções de sacarose com concentrações de 40 a $70{ }^{\circ} \mathrm{Brix}$, durante 180 a 270 minutos. Foi observado que a solução de $40{ }^{\circ}$ Brix proporcionou maior perda do conteúdo de água comparado com as concentrações de 55 e $70{ }^{\circ}$ Brix. $\mathrm{O}$ modelo difusional proposto apresentou um bom ajuste aos dados experimentais, com coeficiente de difusão em torno de $5,02 \times 10^{-11}$ a $1,10 \times 10^{-9} \mathrm{~m}^{2} / \mathrm{s}$ e coeficiente de correlação de 0,90 .
\end{abstract}

\section{INTRODUÇÃO}

A acerola, cujo nome cientifico é Malpighia emarginata $D C$, têm sido uma fruta largamente cultivada nos últimos anos na região nordestina do Brasil. Também conhecida como cereja das Antilhas, por sua origem, é um pequeno fruto de cor vermelha de sabor ácido e levemente doce, que tem assumido grande importância pelo seu valor nutricional, pois é uma fonte natural de vitamina C ácido ascórbico (Silva, 2004).

A desidratação de produtos agrícolas tem a finalidade de preservar, reduzir os custos de embalagem e de transporte, como resultado da diminuição do peso e volume, e aumentar a diversificação do produto no mercado. A desidratação osmótica tem atraído a atenção de muitos desenvolvedores de produtos alimentares, devido à sua boa conservação. Pode ser realizada para se obter diversos tipos de produtos, tais como minimamente processado, produtos intermédios de umidade, ou como um pré-tratamento antes da secagem ou congelamento (Oliver et al., 2012).

Segundo Bellary et al. (2011) a desidratação osmótica é uma tecnologia viável para a impregnação de ingredientes bioativos em alimentos sem alterar a sua estrutura. Aguiar et al. (2002) estudaram desidratação osmótica da banana nanica em solução osmótica de $50{ }^{\circ}$ Brix, temperatura de imersão de 50 a $70{ }^{\circ} \mathrm{C}$, tempo de imersão de 1 a 4 horas seguida da secagem em estufa a $60{ }^{\circ} \mathrm{C}$, por tempos de 4 a $6 \mathrm{~h}$. Observaram que a desidratação osmótica tem baixos custos energéticos comparando a outros métodos desidratação, adapta-se aos pequenos e médios produtores, sendo uma opção tecnológica para a redução das perdas no período entre safras. Além 
disso, a desidratação osmótica é uma técnica rentável para os produtores com a finalidade de mantê-los no meio rural (Vasconcelos, 2010).

A desidratação osmótica consiste em mergulhar o tecido vegetal em soluções hipertônicas, gerando uma troca de massa em dois sentidos: o fluxo de água que difunde do interior da amostra para a solução circunvizinha, e no sentido oposto, um fluxo concomitante da substância osmótica que difunde da solução no tecido desidratado. O terceiro fluxo consiste na perda de alguns sólidos naturais da substância desidratada, como açúcares, ácidos orgânicos, sais minerais, entre outro nutritivo. Este fluxo não apresenta nenhum significado na troca de massa, mas tem uma influência nos valores nutritivos finais (vitamina $\mathrm{C}$ e mineral) e propriedades organolepticas do alimento (sabor, cor e textura). O resultado da troca de massa é uma redução da água do alimento com um aumento simultâneo do ganho dos sólidos e uma mudança da constituição química do alimento desidratado, resultando em um novo produto. A preservação por meio do método osmoconvectivo reduz o consumo de energia em uma faixa de 20 à $30 \%$ quando comparada à secagem convectiva (Lenart, 1996).

Segundo Corrêa et al. (2008), o uso de soluções de sacarose em desidratação osmótica contribuiu para uma redução do teor de umidade, como também um aumento do ganho de sólidos. Gonçalves e Blume (2008) no estudo da desidratação osmótica como tratamento preliminar na secagem de abacaxi observaram, através da analise sensorial, que as características nutricional e sensorial foram preservadas, resultando em um produto com uma grande aceitabilidade na compra e estabilidade no armazenamento.

Segundo Silva et al. (2012) no estudo da transferência de massa durante a desidratação osmótica da acerola observaram que os valores de ganho de sólidos foram muito menores do que os da perda de água.

\subsection{Equação Teórica do Modelo Difusional}

A difusão de água permite a aplicação da Lei de Fick que é expressa em termos do gradiente de umidade. Lewis (1921) sugeriu em seus primeiros estudos que o processo de secagem dos materiais sólidos era difusional. Para geometrias simples e transferência unidirecional, a Lei de Fick pode ser expressa por:

$$
\frac{\partial X}{\partial t}=\frac{1}{r^{q}} \frac{\partial}{\partial r}\left(D r^{q} \frac{\partial X}{\partial r}\right)
$$

Onde: $D$ é o coeficiente de difusão; $q=0$, para placa plana; $q=1$, para cilindro; $q=2$, para esfera; $r$ é a coordenada espacial; $r$ representa o raio da esfera; $t$ o tempo e $X$ é o conteúdo de umidade do material.

A Equação (1) tem sido usada para diversas formas de sólidos na secagem de vários materiais. Crank (1975) e Keey (1997) apresentam as soluções analíticas da Equação (1) para as três formas geométricas. No caso de esfera, a integração desta Equação (1) leva à seguinte equação para a umidade média Equação (2): 


$$
X^{*}=\left(\frac{\bar{X}-X_{e q}}{X_{i}-X_{e q}}\right)=\frac{\sigma}{\pi^{2}} \sum_{n=1}^{\infty} \frac{1}{n^{2}} \exp \left(\frac{-D n^{2} \pi^{2} t}{r^{2}}\right)
$$

Onde: $D$ é o coeficiente de difusão; $n$ é o número de termos da série; $\mathrm{r}$ representa o raio da esfera; $t$ é o tempo; $X_{i}$ conteúdo de umidade inicial (b.s.) $\left(\mathrm{g}_{2} \mathrm{O} / \mathrm{g} \mathrm{ms}\right) ; X^{*}$ conteúdo de umidade do material; $X_{e q}$ é conteúdo de umidade de equilíbrio, (base seca) $\left(\mathrm{g} \mathrm{H}_{2} \mathrm{O} / \mathrm{g} \mathrm{ms}\right) ; X_{i}$ conteúdo de umidade inicial (b.s.) $\left(\mathrm{g} \mathrm{H}_{2} \mathrm{O} / \mathrm{g} \mathrm{ms}\right)$ e $\bar{X}$ conteúdo de umidade do material no instante $t\left(\mathrm{~g} \mathrm{H}_{2} \mathrm{O} / \mathrm{g}\right.$ $\mathrm{ms})$.

A quantidade total de substância que incorpora ou difunde na esfera é determinada pelo modelo difusional de Fick, apresentado analiticamente por Crank (1975). Esta equação (3) é valida tanto para tempos curtos quanto para tempos longos e é dada por:

$$
\frac{M_{t}}{M_{\infty}}=1-\frac{6}{\pi^{2}} \sum_{n=1}^{\infty} \frac{1}{n^{2}} \exp \left(\frac{D n^{2} \pi^{2} t}{r^{2}}\right)
$$

Onde: Designamos que $A=\left(6 / \pi^{2}\right)$ é o parâmetro do modelo difusional de uma esfera; $D$ é o coeficiente de difusão; $M_{t}$ é a quantidade de água difundida com o tempo; $M_{\infty}$ é a quantidade de água difundida no tempo infinito; $n$ é o número de termos da série; $r$ representa o raio da esfera e $t$ o tempo.

Segundo Silva (2004) mediante o método de tentativas foi determinado que nove termos da série da Equação (3) eram suficientes para atingir a convergência. Verificou-se que o parâmetro $(A)$ aproxima-se de $\left(6 / \pi^{2}\right)$ na medida em que se aumentava o número de termos, apresentando uma diferença entre o valor teórico e experimental em torno de $8,63 \%$.

O objetivo do presente trabalho é verificar o efeito do pré-tratamento com água a $93^{\circ} \mathrm{C}$ na taxa de desidratação osmótica da acerola em soluções de sacarose de 40,55 e $70^{\circ}$ Brix e modelar a cinética de desidratação osmótica.

\section{MATERIAL E MÉTODOS}

As frutas foram selecionadas com base no grau de maturidade semelhante, consistência mais firme, tamanho e cores semelhantes, cascas sem fissuras ou manchas. $\mathrm{O}$ branqueamento precedeu os experimentos de desidratação osmótica no qual consistiu na imersão da fruta em um banho de água a $93{ }^{\circ} \mathrm{C}$ por um tempo de 5 segundos, em seguida as frutas foram retiradas e o excesso de água removido com papel absorvente gramatura $28 \mathrm{~g} \cdot \mathrm{m}^{-2}$ e pesada em balança semi-analítica Bel Engineering SSR-600. Os experimentos foram realizados à temperatura ambiente (aproximadamente $28{ }^{\circ} \mathrm{C}$ ). A solução osmótica foi preparada utilizando água destilada e sacarose comercial (açúcar refinado), adquirida no supermercado de João Pessoa-PB, nas concentrações desejada de 40, 55 e 70 Brix. As concentrações das soluções foram determinadas através de um refratômetro manual portátil - Atago N2 e N3. 
Inicialmente foi confeccionada uma cesta cilíndrica em tela de alumínio com altura $9 \mathrm{~cm}$ e diâmetro $8 \mathrm{~cm}$, capacidade para $200 \mathrm{~g}$ de frutas, as acerolas foram colocadas na cesta, com um suporte cuja finalidade era mantê-las totalmente imersas em $500 \mathrm{ml}$ de solução osmótica para uma determinada concentração e tempo de imersão.

Em intervalos regulares de tempo, as frutas foram retiradas da cesta, drenada, enxaguada com água destilada para retirar o excesso da solução, e a água removida suavemente com papel absorvente. Posteriormente foi pesada em balança semi-analítica e imediatamente retornava a solução de sacarose.

Depois do tratamento osmótico, as frutas foram secas com papel absorvente. O teor de umidade foi determinado pela pesagem de amostras de acerola antes e depois de um período de 24 h a $70^{\circ} \mathrm{C}$ em uma estufa, segundo (AOAC, 1997).

A difusividade efetiva da água $(D)$, os valores do parâmetro $(A)$ e os coeficientes de correlação $\left(R^{2}\right)$ foram estimados mediante ajustes dos dados experimentais utilizando o modelo difusional de Fick Equação (3), por regressão não-linear. Onde o valor $\left(6 / \pi^{2}=0,6079\right)$ corresponde à geometria esférica e foi substituído por um parâmetro ajustável $(A)$. O número de termos da série necessário para atingir a convergência foi determinado por tentativas apresentando uma aproximação do parâmetro $A$ (Silva, 2004).

\section{RESULTADOS E DISCUSSÕES}

A Figura 1 (a), (b) e (c) ilustram as curvas do conteúdo de umidade sobre o conteúdo de umidade inicial da acerola desidratada na solução osmótica em função do tempo para as concentrações, 40, 55 e $70{ }^{\circ}$ Brix. As soluções a $40{ }^{\circ}$ Brix proporcionaram perdas do conteúdo de água de 0,9924 e 0,9902 , que são maiores comparados com as soluções a $70{ }^{\circ}$ Brix de 0,9953 e 0,9927 para as desidratações de 180 e 270 minutos, respectivamente. Oliver et al. (2012) no estudo da desidratação osmotica de fatias de maçã observaram uma perda do teor de água e a absorção de sólidos solúveis.

Comparando os valores finais do conteúdo de umidade sobre o conteúdo de umidade inicial, na Figura 1 (a) e (b), podemos observar que o maior tempo de imersão levou a valores mais baixos de umidade no final do processo. O mesmo foi observado por Silva et al. (2011b) na desidratação osmótica da acerola em que o aumento do tempo da desidratação osmótica de 4 para 12 horas resultou em valores mais baixos de umidade.

Pode-se observar que no final da desidratação osmótica na Figura 1(a), as concentrações de 40 e $70^{\circ}$ Brix apresentaram um conteúdo de umidade sobre o conteúdo de umidade inicial 0,9924 e 0,9953 , respectivamente. Na Figura 1(b) para as concentrações de 40 e $70{ }^{\circ}$ Brix proporcionaram um conteúdo de umidade sobre o conteúdo de umidade inicial de 0,9902 e 0,9927, respectivamente. Porém, observa-se que a concentração a $40{ }^{\circ}$ Brix obteve um resultado mais satisfatório comparando com a concentração a $70{ }^{\circ} \mathrm{Brix}$. Em um estudo realizado na desidratação osmótica da manga, Souza Neto et al. (2004) observaram que a transferência de massa foi favorecida pelo uso de concentrações mais elevadas. Lima et al. (2004) observaram na cinética de desidratação osmótica do melão que o aumento da concentração da solução favoreceu a uma maior perda de peso do fruto. Nos estudos dos autores acima citados foram avaliados os frutos sem a pele que o reveste e neste, decidiu-se por conserva-la. 


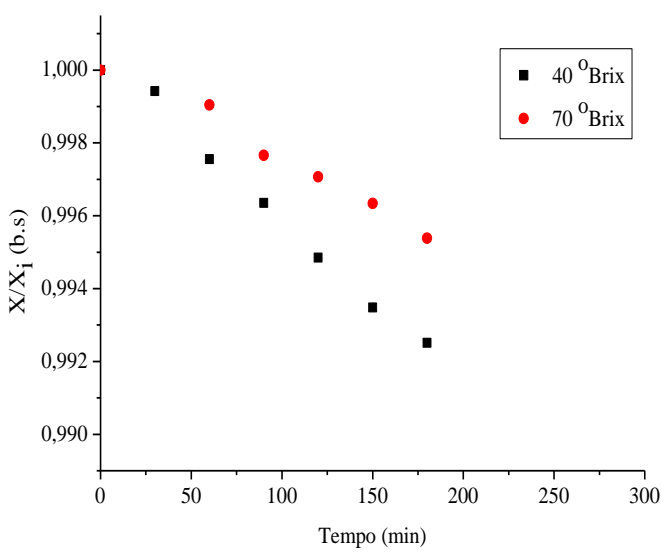

(a)

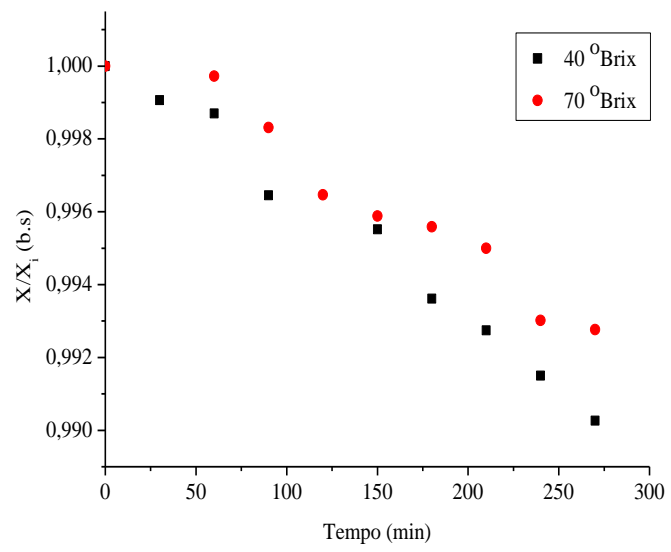

(b)

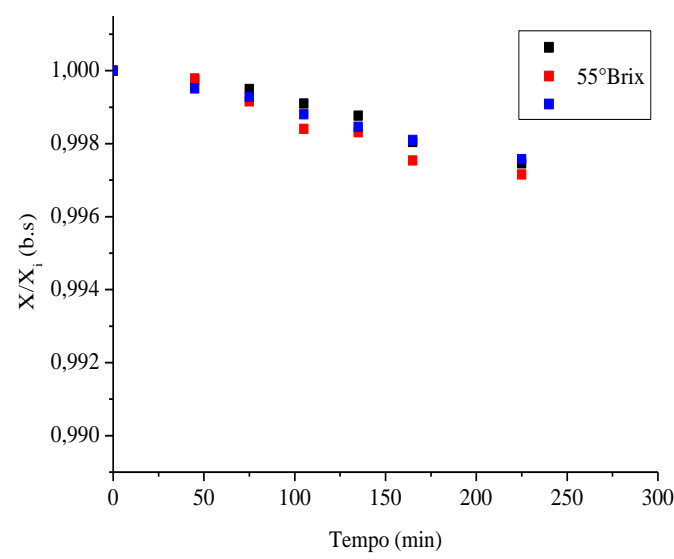

(c)

Figura 1 - Curvas da desidratação osmótica da acerola, após tratamento térmico obtidas em solução de sacarose: (a) Concentrações de 40 e $70{ }^{\circ}$ Brix durante o tempo de imersão 180 minutos, (b) Concentrações de 40 e $70{ }^{\circ}$ Brix durante o tempo de imersão 270 minutos e (c) Repetições referente ao ponto central na concentração de $55^{\circ}$ Brix durante o tempo de imersão 225 minutos.

Foram realizados três repetições da desidratação osmótica para a concentração de $55{ }^{\circ}$ Brix durante 255 min. Na Figura 1(c) observa-se que no tempo final da desidratação osmótica os experimentos apresentaram o conteúdo de umidade sobre o conteúdo de umidade inicial em torno de 0,$9972 ; 0,9975$ e 0,9976 . Observa-se que as perdas de água seguiram uma mesma tendência para os três experimentos.

Segundo Silva et al. (2011b) verificaram as influências dos branqueamentos das abóboras descascadas nas concentrações de sacarose 50 e $65^{\circ}$ Brix durante 0,$5 ; 1 ; 2$ e 3 horas. Observaram que os branqueamentos causaram danos às membranas celulares, resultando em mais espaço para a difusão de sacarose, quando estas membranas são alteradas, parte do conteúdo da célula difunde para a solução osmótica, o que resulta em uma maior impregnação do tecido com solutos a partir 
da solução, neste caso, a sacarose. Nota-se através da Figura 1(a) e (b) que o tratamento térmico pode ter ocasionado danos na película da acerola. Assim, para a solução mais concentração de $70^{\circ}$ Brix provavelmente causou uma maior impregnação do soluto para o interior e película da acerola em comparação a solução menos concentrada de $40^{\circ}$ Brix, resultando em uma menor perda de água na concentração de $70^{\circ}$ Brix e maior perda de água na concentração de $40^{\circ}$ Brix. Silva et al. (2012) estudaram a desidratação osmótica das acerolas em solução de $65^{\circ}$ Brix a temperatura de $27{ }^{\circ} \mathrm{C}$ durante 12 horas, verificaram a formação de uma camada de sacarose sobre a superfície do fruto.

\section{MODELO DIFUSIONAL PARA A CINÉTICA DE DESIDRATAÇÃO OSMÓTICA}

Com o objetivo de modelar a cinética de desidratação osmótica da acerola e calcular o coeficiente de difusividade efetiva foi utilizado o modelo difusional de Fick Equação (3). Utilizando o método de tentativa, citado por (Silva, 2004), foi determinado que quatro termos da série foram suficientes para atingir a convergência. A Figura 2 (a) e (b) apresenta a modelagem da cinética da desidratação osmótica da acerola submetida ao pré-tratamento térmico de 5 segundos.

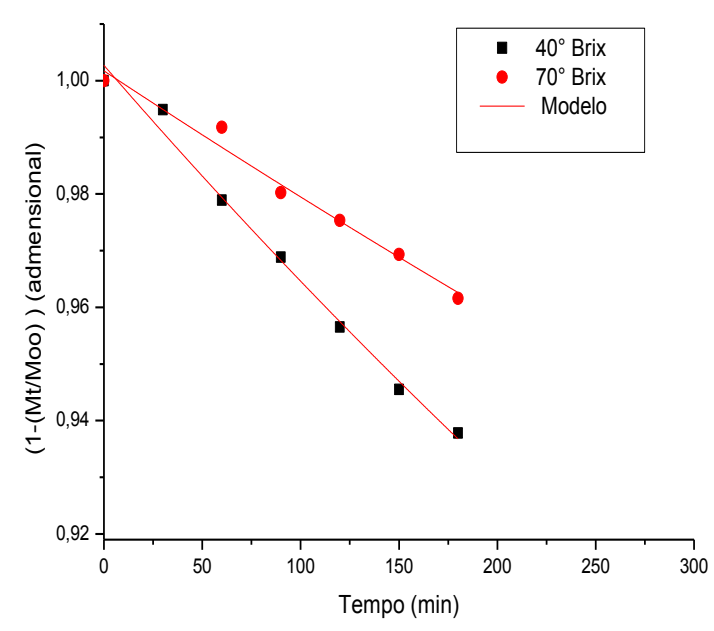

(a)

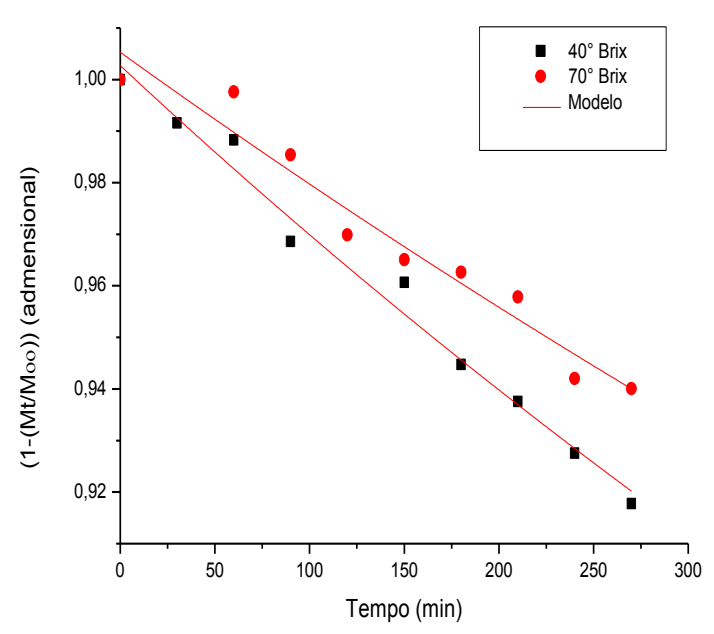

(b)

Figura 2 - Comparação entre os dados experimentais e o modelo difusional para a acerola desidratada em solução osmótica de 40 e $70^{\circ}$ Brix durante um tempo de imersão: (a) 180 minutos e (b) 270 minutos.

A Figura 2 (a) e (b) mostram os ajustes do modelo difusional para a desidratação osmótica nas concentrações de 40 e $70^{\circ}$ Brix. Apesar de alguma oscilação nos pontos experimentais, nota-se que o modelo apresentou em geral um bom ajuste. Observa-se ainda na Tabela 1 que os coeficientes de correlação foram superior a 0,90 salvo no experimento 5 onde foi de 0,86 .

A Tabela 1 mostra os valores do coeficiente de difusividade efetiva da água $(D)$, bem como os respectivos erros da difusão efetiva, os valores do parâmetro $(A)$ e os coeficientes de correlação $\left(R^{2}\right)$, obtidos através da Equação (3), para diferentes combinações de tempo e concentração da 
solução osmótica. Observa-se, através da Tabela 1, que o valor médio obtido para o parâmetro $A$ é 0,7134, nas tentativas com quatro números de termos da série. Verificou-se que o valor de $A$ aproxima-se de $\left(A=6 / \pi^{2}=0,6079\right)$ na medida em que se aumentava o número de termos. Os melhores ajustes foram para as soluções de $40{ }^{\circ}$ Brix, uma vez que os coeficientes de correlação são superiores a 0,982. É possível perceber que os valores obtidos da difusividade efetiva da água ficaram na faixa de $5,02 \times 10^{-11}$ a $1,10 \times 10^{-9} \mathrm{~m}^{2} \mathrm{~s}^{-1}$. Silva (2004) estudou a influência do prétratamento osmótico de 40,55 e $70^{\circ}$ Brix da acerola, nas temperaturas de 30,35 e $45^{\circ} \mathrm{C}$, durante o tempo de 240 minutos obtendo os coeficientes de difusão entre $0,8 \times 10^{-11}$ a $1,33 \times 10^{-10} \mathrm{~m}^{2} \mathrm{~s}^{-1}$.

Tabela 1. Valores do coeficiente de difusividade efetiva e do parâmetro A para diferentes concentrações da solução osmótica em função do tempo.

\begin{tabular}{ccccccc}
\hline $\begin{array}{c}\text { Experimento } \\
\left(\mathrm{N}^{\mathrm{o}}\right)\end{array}$ & $\begin{array}{c}\text { Tempo } \\
(\mathrm{min})\end{array}$ & $\begin{array}{c}\text { Concentração } \\
\left({ }^{\circ} \text { Brix }\right)\end{array}$ & $A=6 / \pi^{2}$ & $\begin{array}{c}D \\
\left(\mathrm{~m}^{2} / \mathrm{s}\right)\end{array}$ & $\begin{array}{c}\text { Erro } D \\
( \pm)\end{array}$ & $R^{2}$ \\
\hline 1 & 180 & 40 & 0,7044 & $8,78 \times 10^{-11}$ & 0,00118 & 0,99007 \\
2 & 180 & 70 & 0,70371 & $5,02 \times 10^{-11}$ & 0,00125 & 0,97663 \\
3 & 270 & 40 & 0,7044 & $1,08 \times 10^{-10}$ & 0,00171 & 0,98298 \\
4 & 270 & 70 & 0,70622 & $8,30 \times 10^{-11}$ & 0,00248 & 0,94709 \\
5 & 225 & 55 & 0,74361 & $1,10 \times 10^{-9}$ & 0,03649 & 0,85536 \\
6 & 225 & 55 & 0,71983 & $6,25 \times 10^{-10}$ & 0,01893 & 0,89153 \\
7 & 225 & 55 & 0,71123 & $5,06 \times 10^{-10}$ & 0,00623 & 0,98293 \\
\hline
\end{tabular}

Nota-se através da Tabela 1 , que nos três experimentos com concentração de $55^{\circ} \mathrm{Brix}$, o maior valor da difusividade mássica efetiva da água foi $1,10 \times 10^{-9} \mathrm{~m}^{2} / \mathrm{s}$ em comparação com os outros dois experimentos. O que pode ter diferenciado o resultado foi a utilização de diversas remessas de frutas, as quais possuem diferenças de umidade inicial.

\section{CONCLUSÃO}

Com base nos resultados apresentados e discutidos, pode-se concluir que a utilização do prétratamento a $93{ }^{\circ} \mathrm{C}$ durante cinco segundos antes da desidratação osmótica foi eficaz por ter ocasionado danos na película da acerola. A utilização deste procedimento para a concentração de $70{ }^{\circ}$ Brix provavelmente causou uma maior impregnação de soluto para o interior e película da acerola em comparação a solução menos concentrada de $40^{\circ}$ Brix, resultando em uma menor perda de água na concentração de $70{ }^{\circ}$ Brix e maior perda de água na concentração de $40{ }^{\circ}$ Brix. O modelo difusional de Fick com quatro termos da série foi adequado para representar o coeficiente de difusão da água, ajustando-se muito bem aos dados experimentais, com coeficiente de correlação variando de 0,891 a 0,990 .

\section{REFERÊNCIAS}

ASSOCIATION OF OFFICIAL ANALYTICAL CHEMISTS - AOAC. Official Methods of Analysis: AOAC: Official methods of analysis. Washington, DC, v. 1, 1990. 
AGUiAR, S. F.; GASPARETO, O. C. P.; MAGALHÃES, M. M. A.; OLIVEIRA, G. L. Estudo da desidratação osmótica da banana nanica. In: XIV CONGRESSO BRASILEIRO DE ENGENHARIA QUÍMICA, 2002, Natal. Anais. Natal: COBEQ, 2002, (CD Rom).

BELLARY, A. N.; SOWBHAGYA, H. B.; RASTOGI, N. K. Osmotic dehydration assisted impregnation of curcuminoids in coconut slices. J. Food Eng., India, v. 105, 3, p. 453-459, 2011.

CORRÊA, J. L. G.; CACCIATORE, F. A.; SILVA, Z. E.; ARAKAKI, T. Desidratação osmótica de acerola (Malpighia emarginata D.C) - Cinética de transferência de massa. Rev. Ci. Agron., v.39, n.3, p.403-409, 2008.

CRANK, J.A. The mathematics of diffusion. 2.ed. Oxford: University Press. 1975, 414p.

GOMES, A. T.; GEREDA, M. P.; VILPOUX, O. Desidratação osmótica: uma tecnologia de baixo custo para o desenvolvimento da agricultura familiar. Rev. Bra. Gestão e des. Regional. G \& DR,v.3, n.3, p.212-226, set-dez/2007.

GONÇALVES, A. A. BLUME, A. R. Efeito da desidratação osmótica como tratamento preliminar na secagem do abacaxi. Est. tec., vol. 4, n 2:124-134, 2008.

KEEY, R.B. Tópicos em transferência de calor e massa. Ava. em cinet. sec., 1997.

LENART, A. Osmo-convective drying of fruits and vegetables: technology and application. Drying Tec., v.14, n.2, p.391-413, 1996.

LEWIS, W.K. The rate of drying of solids materials. In: The Symposium on Drying. The J. I. \& Eng. Che., v.13, n.5, p.427-432, 1921.

LIMA, A. S.; FIGUEIREDO, R. W.; MAIA, G. A.; RIBEIRO, J.; SOUZA NETO, M. A.; SOUZA, A. C. Estudo das variáveis de processo sobre a cinética de desidratação osmótica de melão. Ci. e Tec. Alim., Campinas, v. 24, n. 2, p. 282-286, 2004.

OLIVER, L.; BETORET, N.; FITO, P.; HEINDERS, M. B. J. How to deal with visco-elastic properties of cellular tissues during osmotic dehydration. J. Food Eng. v. 110, pp. 278-288, 2012.

SILVA, V. A. Secagem osmo-convectiva da acerola. 2004. 176p. Tese (Tese de Doutorado em Engenharia de Processos) - Universidade Federal de Campina Grande, Campina Grande, 2004.

SILVA, M. A. C.; CORRÉA, J. L. G.; SILVA, Z. E. Drying kinetics of West Indian Cherry: Influence of osmotic pretreatment. B.CEPPA, Curitiba, v. 29, n. 2, p. 193-202, 2011a.

Silva, K. S.; CAETANO, L. C.; GARCIA, C. C.; ROMERO, J. T.; SANTOS, A. B. and MAURO, M. A. Osmotic dehydration process for low temperature blanched pumpkin. J. Food Eng. v. 105, pp. 56-64, 2011 b.

SILVA, M. A. C.; SILVA, Z. E.; MARINI, V. C. DARCHE, S. Mass transfer during the osmotic dehydration of West Indian cherry. LWT - Food Sci. and Tec., 45 pp. 246- 252, 2012.

SOUZA NETO, M. A.; MAIA, G. A.; LIMA, J. R.; FIGUEIREDO, R. W.; SOUZA FILHO, M. S. M.; LIMA, A. S. Cinética de desidratação osmótica de manga. Ci. Agrot. Lavras, no 10, v. 2; p. 37-44, 2004.

VASCONCElOS, J. I. L. A. Desidratação Osmótica de Figo da Índia (Opuntia fícus indica). 2010. 76p. Dissertação (Mestre em Ciência e Tecnologia de Alimentos) - Universidade Federal Rural de Pernambuco, Recife. 2010. 